\title{
INTERACTIVE RELATIONS OF GENDER, RESIDENCE AND SOCIAL STRATIFICATION WITH TYPES OF AGGRESSION
}

\author{
A. K. M. Rezanur Rahman* \\ Department of Psychology, Baneswar College, Rajshahi, Bangladesh
}

\begin{abstract}
Attempts were made to examine the interactive relations of gender, residence and social stratification with different types of aggressive behaviour. The independent variables were gender, residence and socio-economic status. Different types of the behaviour include physical, verbal, anger, hostile and indirect aggression. A total of 240 respondents between 13 and 16 years of age constituted the sample of the study. The Measure of Aggressive Behaviour (MAB) was used for data collection. The study utilized a $2 \times 2 \times 3$ factorial design consisting of two levels of gender (male/female), two levels of residential background (urban/rural), and three levels of socio-economic status (high/middle/low). The results were computed on each dimension separately using t-tests. The findings revealed interactive relations of gender, residence and social stratification with different types of aggression.
\end{abstract}

Key words: Aggression, antisocial behaviour, gang related violence, autism, attention deficit disorder

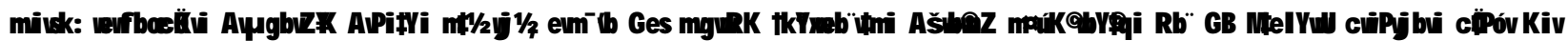

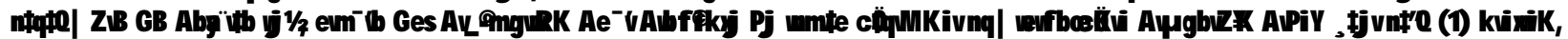

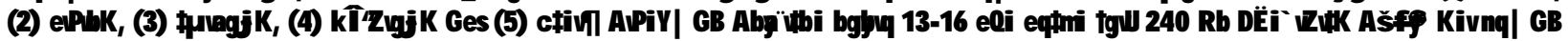

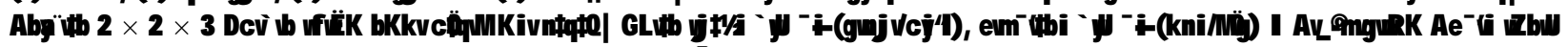

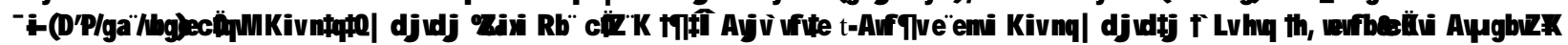
A Pi tYi mot_

\section{Introduction}

It is said that intolerance, self interest and feeling of dominance may lead an individual or a group to behave aggressively. Aggression may be antisocial and pro-social. If an aggressive act results from intent to hurt other person, it is called antisocial aggression. But if an aggressive act is aimed at killing terrorist who has killed an innocent person, it is called prosocial aggression. The prosocial aggression is based on social norms of helping the oppressed persons. Unprovoked criminal acts such as assault and battery, murder, gang beatings and terrorism clearly violate social norms. Hence they are described as prosocial. Acts of law enforcement and appropriate parental discipline are examples of prosocial aggression.

Some aggressive acts fall between prosocial and antisocial. These are called sanctioned aggression. A teacher may punish his disobedient students. A person may hit another person for self-defense. These are the examples of sanctioned aggression. These acts of aggression do not violate moral standards and these are permitted by social norms.

A proper understanding of aggression needs to differentiate aggressive behaviour from aggressive feeling such as anger. Anger is our internal feelings. We may be quite angry inside but we seldom make an effort to hurt another person. Thus our overt behaviour does not always reflect our covert feelings. Society

*Email: moz_psy@yahoo.com discourages and condemns most forms of aggressive behaviour. We can exist only if people control their aggressive feelings most of the time. We cannot allow one person to hit another person, breaking windows or acting violently whenever he feels to do it. Society places strong restraints on such expression. In reality most people who feel angry rarely act aggressively. Hence it is necessary to consider both the factors that increase anger and that restraints anger from being translated into aggressive action. The present investigation has been designed to conduct an empirical investigation to explore the interactive relations of gender, residence and social stratification with different types of aggression.

There are many ways to distinguish between aggressive behaviours. For example, Fraser (1996) argued that aggressive behaviour can be characterized by age of onset. He viewed family environment as one of the most important risk factors in childhood-onset of aggressive behaviour. Children from families that use poor child management style (e.g., harsh punishment, negligence, abuse, acquiescence, etc.) learn poor problem-solving skills from their parents. For example, coercion is modeled (social learning) and acquiescence rewards a child's aggressive reactions (reinforcement). Aggressive behaviour is also rewarded in families where parents employ coercion-acquiescence child management and children in such families are often isolated from 
prosocial peers because they are more likely to use aggressive behaviours to get what they want and to establish social dominance.

Furthermore, Fraser (1996) stated that the adolescentonset type of aggressive behaviours are often more influenced by contextual and systematic factors outside the family, including school, neighborhood, and peer conditions such as hostile relations with teachers, peer pressure to engage in early sexual activity, and involvement with a gang. School climate in which violence and power are valued and poor teaching practices (e.g., coercive teaching or poorly trained staff) are strongly related to children and adolescents' aggressive behaviours. Gang-related violence, in particular, is more strongly associated with local economic, school, and peer factors than with biological and family factors, which are usually the primary risk factors in childhood-onset aggressive behaviour.

Baron (1977) maintained that instrumental aggression is an attempt to injure someone while trying to satisfy some other non-aggressive purposes or desired goals (e.g., obeying the rules of one's gang to obtain their approval), whereas hostile aggression is primarily directed toward the injury of an intended victim. According to Baron (1977), hostile aggression is usually a response to stimuli perceived as aversive, such as a real or imagined insult or a frustrating experience, and often lacks emotional control. In addition, those who show hostile aggression often have a tendency to erroneously infer hostile intentions to others. Coie and Dodge (1986) also distinguished between two types of aggressive adolescents using different terms, namely, the dominant aggressive adolescent (instrumental) and the reactive aggressive adolescent (hostile).

People with hostile aggression are described by psychologists as angry with an inability of controlling their aggression (Baron 1977). Also, people with childhood-onset type aggression have much in common with people with hostile aggression in nature. By the same token, people with instrumental aggression are more likely to have much in common with people with adolescent-onset type aggression. Therefore, it may be assumed that people with hostile aggression will be more likely to show more persistent aggressive behaviour from childhood through adulthood.

However, researchers are not in complete agreement with one another about what causes aggression. Some researchers (Moyer 1976; Sylwester 1999) argue that aggression is an innate and instinctive phenomenon, whereas some claim that aggression must be learned.
Although no one has found a single absolute cause for aggression, there is a general agreement that both nature and nurture are important causes of aggression, and that they interact with and influence each other.

Some causes of aggression are believed to result from biological causes. For example, the amygdala that is an area in the core of the brain plays a role of controlling aggression. If that area is stimulated, a docile organism becomes violent. If that area is blocked, a violent organism becomes docile (Moyer 1976). The hypothalamus also plays a key role in activating our rapid reflexive and often assertive responses to an imminent danger or opportunity (Sylwester 1999).

Testosterone, a male sex hormone that promotes bone growth and muscle mass can also be a possible cause of aggressive behaviours. Testosterone lowers the male voice and helps develop sexual characteristics. It also binds to brain areas that influence behaviour. According to Moyer (1976) testosterone increases aggression in animals. Even though both males and females have testosterone, males have much more than females and are consistently more aggressive than females (Maccoby and Jacklin 1974).

Another possible cause of aggression may be chemical imbalances. Neurotransmitters such as serotonin, dopamine, and norepinephrine play important roles in regulating one's behaviour. Low serotonin levels, for instance, are linked to aggressive behaviours such as fighting, arson, and suicide (Sylwester 1999). The malfunctioning brain system of people with mental problems, such as schizophrenia, attention deficit disorders, and autism, is another cause of social behaviour problems (Sylwester 1999).

However, it should be noted that aggression may be an optional strategy that is determined by a situational context in which the individual finds himself or herself. For example, imagine that one man is in a threatening or irritating situation in which he is surrounded by violent and strong men. Even though his amygdala is stimulated, that person may try to escape instead of attacking those people. Simply speaking, biological causes are likely to create a predisposition of aggressive behaviour. However, a biological cause itself may be incomplete in the explanation of aggressive behaviour.

It is therefore evident that biological causes of aggression should be substantiated by environmental causes of aggression. Most important factors associated with environmental causes of aggression are: home environment, sociocultural factors, media violence, the 
values of school or society, the availability of aggressive objects, and leisure boredom. Olweus (1980) identified three parental qualities that contribute to aggressiveness in boys. The first is the parents' negative attitude toward their sons (e.g., hostility, rejection, or indifference). Second, such parents are usually tolerant of aggressive behaviour in their children and do not set clear boundaries as to what appropriate behaviour is. The third quality is the parents' use of power-assertive methods of discipline. Thus, boys who are frequently subjected to physical punishment, threats, and violent outbursts of their parents are more likely to be aggressive. Bowers et al. (1994) posited that parents who practiced inconsistent or highly aversive discipline techniques, coupled with physical punishment, were more likely to have a child who would be aggressive toward others. Poor parent discipline and monitoring practices may also lead to childhood aggressive behaviours. Olweus (1993) pointed out that family problems, including frequent conflicts between the parents, divorce, psychological illness, and alcohol problems, might also contribute to children's aggressive behaviours.

Sociocultural factors such as changes in family roles, divorce, child abuse, unemployed parents, and community racial tension are often regarded as contributing factors to personal violence in the schools. In addition, urban society tends to be violent, and some aspects of this violence overflow into the schools (Nuttal and Kalesnik 1987). Poverty may be another important factor in aggression. Poverty decreases the essential resources necessary for social development and increases the stressors that impede effective parenting and problem solving (Nuttal and Kalesnik 1987).

In addition, aggressive behaviours in schools may be influenced by policies and staff attitudes that foster and reinforce violence through the values promoted by an institution reflects into the values of the dominant group in society. Byrne (1993) examined aggressiveness in boys, in single sex boys' schools. In general, boys' schools are more explicitly built on 'male' values. According to the study results, physicality was not only used as a means of intimidation among the boys, but also as a way of making social contact. Apart from physical aggression, a great deal of verbal abuse was heard. Some men teachers commented on the way in which they thought aggression among the boys reflected the authoritarian structures in the school, and referred to the contradictory situation of a teacher threatening a boy with physical punishment for bullying another boy. Competitiveness was another major element of boys' aggression in schools. Physical strength and power were also seen as part of stereotypical male attributes, and aggressive behaviour such as bullying was a major way in which boys were able to demonstrate their manliness (Byrne 1993).

Thus, excessive competition is another possible factor that explains the learning of aggressive behaviour. However, Oliver and Hazler (1992) concluded that the excessive competition fostered in American schools is to the detriment of interpersonal relationships. According to Hoover et al. (1992) competitiveness and regimentation have also been blamed in part for an increase in the rate of students' aggressive behaviour in Japan.

Numerous studies have been conducted to examine the relationship between media violence and aggressive behaviour. Specifically, since 1955, about 1,000 studies, reports, and commentaries concerning the impact of television violence have been published. The cumulative research clearly demonstrates a correlation between viewing violence and aggressive behaviour (Tepperman 1997). In recent years, the effects of other types of media violence, such as video games, radio, music videos, books, and comics, have been investigated as they are related to children's development. Although some of the research is inconclusive and contradictory, the majority of the research has indicated a positive relationship between adolescent aggressive behaviours and media violence (Tepperman 1997).

It is important to note that aggression in children is due to availability of aggressive objects. The mere presence of aggressive stimuli can increase the probability of aggression. Berkowitz (1981) articulated that an angry person can pull the trigger of a gun, but the trigger can also pull the finger. Guns, bombs, and any other objects that can be used as weapons are examples of aggressive objects.

Archer and Gartner (1984) in their cross-national study of violence found that the homicide rate in countries all over the world is highly correlated with the availability of handguns. Aronson et al. (1997) also proposed that lethal violence, especially involving guns, is a major part of American society and therefore plays a major role in the expectations and fantasies of American youngsters.

Alcohol may also be included in this category because it tends to lower inhibitions against committing aggressive behaviours (Desmond 1987). Alcohol can be regarded as an available aggressive object, too. For example, about one-third of youth committing serious crimes consumed alcohol just before the offense (Aronson et al. 1997). 
During the period of adolescence, leisure activities are particularly important because in addition to providing opportunities to socialize, they provide adolescents with good opportunities to explore and form their autonomy and identity (Iso-Ahola and Crowly 1991). However, the lack of leisure repertoires or a perceived boredom in adolescents' leisure time may lead to involvement in deviant behaviours such as violence and crimes. Mukerjee and Dagger (1990) claimed that leisure boredom may be correlated to an increase in adolescent participation in crime.

Iso-Ahola and Crowley (1991) found that people with aggressive behaviour may be engaged in harmful activities (i.e., drug abuse, smoking, alcoholism, and juvenile delinquency) to escape from boredom in their free time. Their finding was consistent with other previous studies having shown a positive relationship between boredom susceptibility and alcohol use, smoking and deviant behaviour (Orcutt 1984; Smith and Caldwell 1989).

Although there are still some arguments between nature and nurture, there is a general agreement that both elements are important causes of aggression. That is, it is generally accepted that nature and nurture influence as well as interact each other.

In the perspective of these empirical findings about the nature sources and causes of aggression an attempt has been made to conceptualize different types of aggression to be used in the present study. These include physical, verbal, anger, hostile and indirect aggression behaviour. The conceptualization of these types of aggression is described below.

Physical aggression (PA): It has been conceptualized as anger expressed through physical movement of the body. Thus physical aggression consists of using force against the person, objects or situation. Fighting with persons or destruction of objects or attacking the situation may be regarded as PA.

Verbal aggression (VA): It has been conceptualized as aggression expressed through language. It involves emotional outburst in the form of verbal expression. Thus hot talk with the opponent may be considered as a VA. Loud voice mixed with anger at the time of argumentation may also be regarded as VA. Similarly, use of hostile language is another example of VA.

Hostile aggression (HA): It has been conceptualized as resentment in situations with other persons. It involves when a person cannot tolerate his opponent. HA results in social isolation. A person who is hostile to his environment expresses HA. A person may express HA in the absence of proper objects in the situation or environment. Thus a psychotic patient with the symptom of paranoia may express HA.

Anger aggression (AA): It has been conceptualized as a physical symptom in an excited condition. When a person is agitated due to imbalance in the inter-group relationships, it is called an AA. In such situations, the person looses his sense of control.

Indirect aggression (IA): IA has been conceptualized as the expression of anger without direct involvement with the person, object or situation. This type of aggression involves unequal relationships. It also refers to the fact that the person does not like to disturb the environment. Thus IA refers to behavioural expression of anger without direct confrontation with the opponent. The present study has utilized these types of aggression in order to explore interactive relations of gender, residence and social stratification.

Objectives: Specific objectives of the study were: (1) To study the effect of gender issue on aggressive behaviour; (2) To find out the effect of socioeconomic status on aggressive behaviour; and (3) To reflect on residential background as a causative factor of aggression.

Hypothesis: Gender, residence and social stratification would have interactive relations with different types of aggression.

\section{Methods and Procedures}

Sample: A total of 240 respondents between 13 and 16 years of age constituted the sample of the present study. They were equally divided into males and females. Each group was divided into urban and rural taking equal number of respondents from each residential background. Then each subgroup was equally divided into high, middle and low socio-economic status on the basis of social stratification.

Instrument: Following Buss and Perry (1992) an Measure of Aggressive Behaviour (MAB) was developed (Rahman 2003). This MAB contained 25 items which were divided into 5 dimensions such as PA (five items), VA (nine items), HA (five items), AA (three items) and IA (three items). Hypothetical situations were constructed on each item. Each item was followed by 5 alternatives ranging from totally true to totally false. Totally true was given 5 points, true 4 
points, neutral 3 points, false 2 points and totally false 1 point. The highest possible score (HPS) was $25 \times 5=$ 125 and the lowest possible score (LPS) was $25 \times 1$ =25. Aggressive Behaviour Score (ABS) was worked out using the following formula.

$$
\mathrm{ABS}=\frac{\mathrm{HPS}-\mathrm{LPS}}{2}+\mathrm{LPS}=\frac{125-25}{2}+25=75
$$

Hence, a score following 75 or above was regarded as ABS.

The correlation coefficient for split-half reliability was found 0.37. When Spearman-Brown formula was used, the correlation coefficient was found to increase from 0.37 to 0.54 . The MAB was confirmed by validation at several stages. Items were constructed through open-end questionnaire. This indicated the content validity of MAB. Secondly, the scrutiny of each item was done by the judges. This procedure provided face validity for the MAB.

Design of the study: The present study used a $2 \times 2 \times 3$ factorial design consisting of two levels of gender (male/female), two levels of residential background (urban/rural), and three levels of socio-economic status (high/middle/low).

Procedure for data collection: The MAB was administered on 240 respondents. The investigator contacted each respondent individually. Before administering the MAB, proper rapport was established. The booklet of MAB was given to each respondent separately. The respondent was required to read the instruction given on the front page of the booklet. In first phase, 20 male respondents with high socioeconomic status from urban residential background were selected for data collection. In the second phase, 20 male respondents with middle socioeconomic status from urban residential background were selected. In the third phase, 20 male respondents with low socioeconomic status from urban residential background were considered. Following this procedure, 20 male respondents with high socioeconomic status from rural residential background, 20 male respondents with middle socioeconomic status from rural residential background and 20 male respondents with low socioeconomic status from rural residential background were chosen. Similar procedure was maintained for female respondents. As soon as the data collection was completed, coding was done properly for statistical analysis of the data.

\section{Results and Discussion}

The MAB contains five dimensions namely PA, VA, HA, $\mathrm{AA}$ and IA. The results were computed on each dimension separately using t-tests.

PA: The results presented in Table 1 show comparisons between groups. Female respondents of middle socioeconomic status with rural residential background $(\mathrm{M}=16.85)$ expressed significantly more PA $(\mathrm{t}=2.31$, $\mathrm{df}=38, \mathrm{P}<0.05$ ) compared to the male counterparts $(\mathrm{M}=14.40)$. Similarly, female respondents of low socioeconomic status with urban residential background $(M=17.95)$ expressed significantly more PA $(t=2.15$, $\mathrm{df}=38, \quad \mathrm{P}<0.05)$ in comparison with the male respondents of similar background $(\mathrm{M}=15.80)$.

Table 1. Mean differences between MHU vs FHU, MHR vs FHR, MMU vs FMU, MMR vs FMR, MLU vs FLU and MLR vs FLR on the scores of PA $(N=20$ for each group).

\begin{tabular}{|l|l|l|l|l|l|l|}
\hline & Mean & SD & & Mean & SD & t-values \\
\hline MHU & 14.55 & 3.33 & FHU & 15.40 & 3.01 & $0.83 n s$ \\
\hline MHR & 16.90 & 2.55 & FHR & 15.30 & 3.07 & $1.75 \mathrm{~ns}$ \\
\hline MMU & 14.00 & 2.78 & FMU & 15.90 & 3.82 & $1.57 \mathrm{~ns}$ \\
\hline MMR & 14.40 & 3.46 & FMR & 16.85 & 3.11 & $2.31^{*}$ \\
\hline MLU & 15.80 & 2.94 & FLU & 17.95 & 3.28 & $2.15^{*}$ \\
\hline MLR & 16.80 & 2.46 & FLR & 15.55 & 2.36 & $1.62 \mathrm{~ns}$ \\
\hline
\end{tabular}

Ns= not significant; $*=\mathrm{P}<0.05$

VA: The results (Table 2) showed that male respondents of high socio-economic status with rural residential background $(\mathrm{M}=31.10)$ expressed significantly more VA $(\mathrm{t}=3.14, \mathrm{df}=38, \mathrm{P}<0.01)$ compared to the female respondents of high socioeconomic status with rural residential background $(\mathrm{M}=28.55)$. Whereas female respondents of low socio-economic status with urban residential background $(\mathrm{M}=31.30)$ expressed significantly more VA $(\mathrm{t}=4.38, \mathrm{df}=38, \mathrm{P}<0.01)$ as compared to the male respondents of low socioeconomic status with urban residential background (M=26.35).

Table 2. Mean differences between MHU vs FHU, MHR vs FHR, MMU vs FMU, MMR vs FMR, MLU vs FLU and MLR vs FLR on the scores of VA $(N=20$ for each group).

\begin{tabular}{|l|l|l|l|l|l|l|}
\hline & Mean & SD & & Mean & SD & t-values \\
\hline MHU & 27.85 & 3.79 & FHU & 30.05 & 3.43 & $1.89 n s$ \\
\hline MHR & 31.10 & 2.83 & FHR & 28.55 & 2.14 & $3.14^{* *}$ \\
\hline MMU & 28.60 & 4.54 & FMU & 28.10 & 4.09 & $0.35 n s$ \\
\hline MMR & 27.95 & 5.32 & FMR & 28.35 & 3.75 & $0.27 n s$ \\
\hline MLU & 26.35 & 3.97 & FLU & 31.30 & 2.97 & $4.38^{* *}$ \\
\hline MLR & 28.90 & 5.31 & FLR & 26.70 & 3.08 & $1.57 n s$ \\
\hline
\end{tabular}

Ns= not significant; $* *=\mathrm{P}<0.01$ 
HA: Data on Table 3 exhibit that the female respondents of high socioeconomic status with urban residential background $(\mathrm{M}=14.15)$ expressed significantly more HA $(\mathrm{t}=2.01, \mathrm{df}=38, \mathrm{P}<0.05)$ as compared to the male respondents of high socioeconomic status with urban residential background (M=11.85). Similarly, female respondents of low socioeconomic status with urban residential background $(\mathrm{M}=14.55)$ expressed significantly more HA $(\mathrm{t}=5.27$, $\mathrm{df}=38, \mathrm{P}<0.01$ ) as compared to the male respondents of low socioeconomic status with urban residential background ( $\mathrm{M}=9.80)$.

Table 3. Mean differences between MHU vs FHU, MHR vs FHR, MMU vs FMU, MMR vs FMR, MLU vs FLU and MLR vs FLR on the scores of HA $(N=20$ for each group).

\begin{tabular}{|l|l|l|l|l|l|l|}
\hline & \multicolumn{1}{|c|}{ Mean } & \multicolumn{1}{|c|}{ SD } & & Mean & \multicolumn{1}{c|}{ SD } & t-values \\
\hline MHU & 11.85 & 2.90 & FHU & 14.15 & 4.11 & $2.01^{*}$ \\
\hline MHR & 11.75 & 2.57 & FHR & 12.35 & 4.28 & $0.52 \mathrm{~ns}$ \\
\hline MMU & 11.70 & 3.33 & FMU & 12.85 & 2.97 & $1.13 \mathrm{~ns}$ \\
\hline MMR & 12.00 & 3.89 & FMR & 12.80 & 2.80 & $0.73 \mathrm{~ns}$ \\
\hline MLU & 9.80 & 2.06 & FLU & 14.55 & 3.38 & $5.27^{* *}$ \\
\hline MLR & 13.35 & 4.07 & FLR & 11.30 & 2.39 & $1.89 n \mathrm{~ns}$ \\
\hline
\end{tabular}

Ns= not significant; $*=\mathrm{P}<0.05 ; * *=\mathrm{P}<0.01$

AA: Results on AA (Table 4) showed that female respondents of high socioeconomic status with urban residential background $(\mathrm{M}=11.30)$ expressed significantly more AA $(\mathrm{t}=4.70, \mathrm{df}=38, \mathrm{P}<0.01)$ compared to the male respondents of high socioeconomic status with urban residential background $(\mathrm{M}=8.10)$. Similarly, female respondents of low socioeconomic status with urban residential background $(\mathrm{M}=9.80)$ expressed significantly more AA ( $\mathrm{t}=3.75, \mathrm{df}=38, \mathrm{P}<0.01)$ as compared to male respondents of low socioeconomic status with urban residential background ( $\mathrm{M}=7.40)$.

Table 4. Mean differences between MHU vs FHU, MHR vs FHR, MMU vs FMU, MMR vs FMR, MLU vs FLU and MLR vs FLR on the scores of AA $(N=20$ for each group).

\begin{tabular}{|l|l|l|l|l|l|l|}
\hline & Mean & SD & & Mean & SD & t-values \\
\hline MHU & 8.10 & 2.23 & FHU & 11.30 & 2.00 & $4.70^{* *}$ \\
\hline MHR & 9.95 & 2.13 & FHR & 9.20 & 2.36 & $1.04 \mathrm{~ns}$ \\
\hline MMU & 8.65 & 2.48 & FMU & 9.50 & 2.82 & $1.00 \mathrm{~ns}$ \\
\hline MMR & 9.10 & 2.09 & FMR & 10.10 & 1.73 & $1.66 \mathrm{~ns}$ \\
\hline MLU & 7.40 & 1.96 & FLU & 9.80 & 2.06 & $3.75^{* *}$ \\
\hline MLR & 8.80 & 2.11 & FLR & 8.70 & 1.85 & $0.15 \mathrm{~ns}$ \\
\hline
\end{tabular}

Ns $=$ not significant; $* *=\mathrm{P}<0.01$
IA: Results on IA (Table 5) showed that male respondents of high socioeconomic status with rural residential background $(\mathrm{M}=11.50)$ expressed significantly more IA $(\mathrm{t}=2.84, \mathrm{df}=38, \mathrm{P}<0.01)$ as compared to female respondents of high socioeconomic status with rural residential background $(M=9.45)$. But, female respondents of low socioeconomic status with urban residential background $(\mathrm{M}=10.75)$ expressed significantly more IA $(\mathrm{t}=3.90, \mathrm{df}=38, \mathrm{P}<0.01)$ as compared to male respondents of low socioeconomic status with urban residential background ( $M=8.60)$.

Table 5. Mean differences between MHU vs FHU, MHR vs FHR, MMU vs FMU, MMR vs FMR, MLU vs FLU and MLR vs FLR on the scores of IA $(N=20$ for each group).

\begin{tabular}{|l|l|l|l|l|l|l|}
\hline & \multicolumn{1}{|c|}{ Mean } & \multicolumn{1}{c|}{ SD } & & \multicolumn{1}{c|}{ Mean } & \multicolumn{1}{c|}{ SD } & t-values \\
\hline MHU & 10.80 & 2.92 & FHU & 10.95 & 2.01 & $0.18 \mathrm{~ns}$ \\
\hline MHR & 11.50 & 1.99 & FHR & 9.45 & 2.49 & $2.84^{* *}$ \\
\hline MMU & 10.00 & 2.00 & FMU & 10.00 & 1.58 & $0.00 \mathrm{~ns}$ \\
\hline MMR & 9.15 & 2.41 & FMR & 10.10 & 2.07 & $1.31 \mathrm{~ns}$ \\
\hline MLU & 8.60 & 1.83 & FLU & 10.75 & 1.64 & $3.90^{* *}$ \\
\hline MLR & 10.60 & 2.58 & FLR & 9.50 & 1.72 & $1.57 \mathrm{~ns}$ \\
\hline
\end{tabular}

$\mathrm{Ns}=$ not significant; $* *=\mathrm{P}<0.01$

The present results have revealed an array of diversified findings on PA, VA, HA, AA and IA. In case of PA for males, it was found that the respondents of high socioeconomic status and low socioeconomic status with rural residential background expressed highest aggression compared to other groups. But in case of females, it was found that the respondents of low socioeconomic status with urban residential background expressed the highest PA in comparison to respondents of high socioeconomic status with urban and rural as well as the respondents of low socioeconomic status with rural residential background. These findings show the saliency of residential background in PA. In case of VA for males, on the other hand, respondents of high socioeconomic status with rural residential background expressed the highest aggression in comparison with the other relevant groups. But in case of females, respondents of low socioeconomic status with urban residential background expressed the highest VA followed by respondents of high socioeconomic status with urban residential background. It is thus obvious from the study that residential background is an important variable for affecting VA in highest intensity.

In case of HA for males, respondents of low socioeconomic status with urban residential background were found to express least aggression in comparison with the other relevant groups. Thus, respondents of low 
socioeconomic status with rural residential background expressed the highest HA. Similarly, for females, respondents of high socioeconomic status with urban residential background expressed the highest HA. Apparently the urban residential background has emerged as an important psycho-social factor to account for the HA. For AA in males, respondents of high socioeconomic status with rural residential background expressed the highest aggression followed by respondents of middle socioeconomic status with rural residential background and least by the respondents of low socioeconomic status with urban residential background. But in case of females, respondents of high socioeconomic status with urban residential background expressed the highest AA followed by the respondents of middle socioeconomic status with rural residential background and least by the respondents of low socioeconomic status with rural residential background. In consideration of these diverse findings, it may be concluded that the socioeconomic status and residential background have joint effect to account for AA.

In case of IA for males, respondents of high socioeconomic status with rural residential background were found to express the highest aggression and least by the respondents of low socioeconomic status with urban residential background expressed the least aggression. For females, however, the respondents of high socioeconomic status with urban residential background expressed the highest IA and the respondents of high socioeconomic status with rural residential background expressed the least IA. So, males and females were found to express differential amount of IA conditioned by socioeconomic status and residential background.

Between-group comparisons on PA have shown that female respondents of middle socioeconomic status with rural residential background expressed more aggression than their counterpart male respondents. Similarly, female respondents of low socioeconomic status were found to express more aggression than their counterpart male respondents. These findings are indicative of the fact that women express PA in higher intensity than men. Similar comparisons on VA have shown that male respondents of high socioeconomic status with rural residential background were more aggressive than their female counterparts. But female respondents of low socioeconomic status with urban residential background expressed more VA than their counterpart male respondents. A probe into these findings appears to indicate that socioeconomic status and residential background may account for VA in men and women.
Thus social stratification and residence have emerged as important factor in the study of VA. Findings on HA have provided partial support to the prediction that women are more aggression than men. The female respondents of high socioeconomic status with urban residential background were more aggressive than their counterpart male respondents. Similarly, female respondents of low socioeconomic status with urban residential background were found to express more HA than their counterpart male respondents. These findings about HA show that urban residential background as well as high and low socioeconomic status play an important role for inducing differentiation in HA for men and women.

Findings on AA have also provided partial support to the hypothesis that women would express more aggression than men. It was found that female respondents of high socioeconomic status with urban residential background were more aggressive than their male counterparts. Similarly, female respondents of low socioeconomic status with urban residential background were found to express more AA than their counterpart male respondents. Thus the respondents of high and low socioeconomic status from urban residential background exhibited differentiation in AA for women than men. In case of IA however, male respondents of high socioeconomic status with rural residential background exhibited more aggression than the female respondents. But, female respondents of low socioeconomic status with urban residential background were found to express more IA than the male respondents. These findings demonstrate that the relationships between gender, socioeconomic status and residential background are complex in the study of IA. In fact, these psychosocial variables have emerged as important factors positively related with the prediction of aggression. In other words, the dynamic, functional, and domain-specific nature of psychosocial variables has highlighted the differential nature of aggression (Baumeister and Boden 1998).

\section{Conclusions}

The results of the present study demonstrate that the relationships among different dimensions of the physical, verbal, hostile, anger and indirect aggression behaviours are complex. The generic value of aggression is difficult due to overlapping relationships among different dimensions of aggression. Thus relationships among these dimensions may be regarded as positively correlated and may be used as predictive of aggression. In other words, the absence of inverse relation of these 
dimensions of aggression indicates that the findings of the present study are embedded in the psychosocial factors of aggression. In the light of these arguments, it can be said that the dynamic, functional and domainspecific nature of aggression will be highlighted through future research in the social context of Bangladesh.

\section{References}

Archer D, Gartner R. 1984. Violence and Crime in Cross-national Perspective. Yale University Press, New Heaven, CT.

Aronson E, Wilson TD, Akert RM. 1997. Social Psychology. Longman, Inc. New York.

Baron R. 1977. Human Aggression. Plenum, New York.

Berkowitz L. 1981. How guns control us. Psychol Today 11-12.

Bowers L, Smith PK, Binney V. 1994. Perceived family relationships of bullies, victims and bully/victims in middle childhood. J Social Pers Relationships 11, 215-232.

Buss AH, Perry MP. 1992. The aggression questionnaire. J Pers Social Psychol 63, 452-459.

Byrne B. 1993. Coping with Bullying in Schools. The Columbia Press, Dublin.

Coie J, Dodge K. 1986. Hostile and instrumentally aggressive children: A social information processing perspective. Paper presented at the annual meeting of the American Psychological Association. Plenum. New York.

Desmond EW. 1987. Out in the open. Time (Nov. 30), 80-90.

Fraser MW. 1996. Aggressive behaviour in childhood and early adolescence: An ecological-developmental perspective on youth violence. Social Work 41, 347-361.

Hoover JH, Oliver R, Hazler RJ. 1992. Bullying: perceptions of adolescent victims in the Midwestern USA. School Psychol Int 13, 5-16.
Iso-Ahola SE, Crowly ED. 1991. Adolescent substance abuse and leisure time boredom. J Leisure Res 23, 260-271.

Maccoby EE, Jaclkin CN. 1974. The Psychology of Sex Differences. Stanford University Press, Stanford, CA.

Moyer KE. 1976. The Psychology of Aggression. Harper \& Row, New York.

Mukerjee SK, Dagger D. 1990. The Size of the Crime Problem in Australia (2nd edn.). Australian Institute of Criminology, Canberra, Australia.

Nuttal EV, Kalesnik J. 1987. Personal violence in the schools: The role of the counselor. J Counseling Dev 65, 372-375.

Olweus D. 1980. Familial and temperamental determinants of aggressive behavior in adolescent boys: A causal analysis. Dev Psychol 16, 644-660.

Olweus D. 1993. Bullying at School. Blackwell, Cambridge, UK.

Orcutt JD. 1984. Contrasting effects of two kinds of boredom on alcohol use. J Drug Issues 14, 161-173.

Rahman AKMR. 2003. Psycho-social Factors in Aggressive Behavior in Males and Females in Bangladesh. Unpub. M.Phil. Thesis, Dept. of Psychology, Rajshahi Univ. Bangladesh.

Smith EA, Caldwell LL. 1989. The perceived quality of leisure experiences among smoking and nonsmoking adolescents. J Early Adol 12, 319-332.

Sylwester R. 1999. In search of the roots of adolescent aggression. Edu Leadership 57, 65-70.

Tepperman J. 1997. What do children learn from media violence? Children's Advocate Available: http://www.4children.org/news/1-97toxl.htm . 